\title{
The Evaluation of One Health Initiative on Zoonoses Prevention and Control Program in Indonesia
}

\author{
Dhony Kartika Nugroho \\ Directorate General of Livestock and Animal \\ Health Services \\ Ministry of Agriculture \\ Jakarta, Indonesia \\ dknugros@gmail.com
}

Ardilasunu Wicaksono

Division of Veterinary Public Health and

Epidemiology

$I P B$ University

Bogor, Indonesia

vetsunuedu@gmail.com

Andri Jatikusumah

Emergency Center for Transboundary Animal Diseases

The Food and Agriculture Organization of the United Nations

Jakarta, Indonesia

a.jatikusumah@gmail.com

\author{
Muhammad Muharam Hidayat \\ Directorate General of Livestock and Animal \\ Health Services \\ Ministry of Agriculture \\ Jakarta, Indonesia \\ mm.hidayat.andi@gmail.com
}

\author{
Wahid Fakhri Husein \\ Emergency Center for Transboundary \\ Animal Diseases \\ The Food and Agriculture Organization of \\ the United Nations \\ Jakarta, Indonesia \\ w.fakhri.h@gmail.com
}

\author{
Chaerul Basri \\ Division of Veterinary Public Health and \\ Epidemiology \\ $I P B$ University \\ Bogor, Indonesia \\ chaerulbasri@gmail.com
}

\author{
Ratmoko Eko Saputro \\ Emergency Center for Transboundary \\ Animal Diseases \\ The Food and Agriculture Organization of \\ the United Nations \\ Jakarta, Indonesia \\ ratmokoekosaputro@yahoo.co.id
}

Pebi Purwo Suseno

Directorate General of Livestock and

Animal Health Services

Ministry of Agriculture

Jakarta, Indonesia

pebi212@gmail.com

\author{
Damian Tago Pacheco \\ Emergency Center for Transboundary \\ Animal Diseases \\ The Food and Agriculture Organization \\ of the United Nations, Regional Office for \\ Asia and the Pacific \\ Bangkok, Thailand \\ damian.tagopacheco@fao.org \\ Etih Sudarnika \\ Division of Veterinary Public Health and \\ Epidemiology \\ IPB University \\ Bogor, Indonesia \\ etih23@yahoo.com
}

\author{
Ahmad Gozali \\ Emergency Center for Transboundary \\ Animal Diseases \\ The Food and Agriculture Organization \\ of the United Nations \\ Jakarta, Indonesia \\ gozalivet@gmail.com \\ Elly Sawitri \\ Emergency Center for Transboundary \\ Animal Diseases \\ The Food and Agriculture Organization \\ of the United Nations \\ Jakarta, Indonesia \\ ellysawitri@yahoo.com
}

\begin{abstract}
Since 2017, a zoonoses prevention and control programme has been implemented in four pilot districts in Indonesia adopting a One Health $(\mathrm{OH})$ approach, involving officers from the public health, animal health, and wildlife sectors. After a series of trainings, coordination among sectors has been enhanced and disease information shared among all sectors and used to guide rabies risk mitigation efforts. The objective of the current study was to evaluate the OH capacity building program in the pilot districts of Minahasa, Boyolali, Ketapang and Bengkalis. The initiative was assessed using the questionnaire data collected from each district and utilizing a framework developed by the Network for Evaluation of One Health (NEOH). The OH-index is used as an estimation of the degree to which $\mathrm{OH}$ is integrated into the operations and supporting infrastructure of the initiative. The results of this assessment show that the zoonoses prevention and control programme in Indonesia incorporates effectively the $\mathrm{OH}$ approach, both in its operations and the associated infrastructure. According to the data collected in four pilot areas, the initiative has a $\mathrm{OH}$-ness index score of 0.74. This number indicates that this programme is a good example of how $\mathrm{OH}$ can be implemented in Indonesia.
\end{abstract}

Keywords-Zoonoses, One Health, OH-ness, OH-index, Indonesia

\section{INTRODUCTION}

Over the past two decades, our knowledge of the origin and emergence of diseases has improved. It has been recognized that wildlife reservoirs play a role as the source of potential pathogens, and the importance of the interface between humans, domestic and wild animals in crossspecies transmission of zoonotic diseases has been described [1].

As a consequence, the One Health $(\mathrm{OH})$ concept has received growing attention around the world [2] as an approach to address challenges at the human-animalenvironment interface, such as emerging and zoonotic diseases (e.g. Ebola, Avian Influenza, and Rabies) [3], antimicrobial resistance [4], as well as food safety and food security [5]. However, successful examples of operationalizing $\mathrm{OH}$ are limited, and multi-agency coordination is one of the main challenges [6]. 
It is difficult to develop an integrated approach due to the existing, historically contingent, separation of sectors and disciplines. Moreover, the realization of its benefits can be delayed relative to its costs, which makes coordination more challenging. Some evidence is needed to promote the value of these integrated and transdisciplinary approaches to governments, researchers, funding bodies, and stakeholders [7].

Since 2017, a $\mathrm{OH}$ capacity building programme has been implemented in four pilot districts in Indonesia adopting a $\mathrm{OH}$ approach, involving officers from the public health, animal health, and environment and forestry sectors in four districts (across four different provinces/islands), namely Minahasa, Boyolali, Ketapang, and Bengkalis. The objective of the programme is to enhance networking among different sectors and promote coordination of disease control activities through a series of trainings. All sectors are encouraged to share disease information in order to guide efficient risk mitigation efforts [8].

The objective of the current study was to evaluate the $\mathrm{OH}$ capacity building program in the pilot districts of Minahasa, Boyolali, Ketapang and Bengkalis.

\section{MATERIALS AND METHODS}

Given the nature of the initiative (capacity building) and the limited resources, the Network for Evaluation of One Health (NEOH) framework was adopted to conduct a self-assessment and estimate the $\mathrm{OH}$-ness of the initiative, i.e., the implementation of operations and infrastructure contributing to the $\mathrm{OH}$ initiative.

Through a series of workshops, the evaluation team consulted stakeholders and developed questionnaires to gather additional data from $\mathrm{OH}$ implementers in the four pilot districts. Then, the degree to which the initiative integrated a $\mathrm{OH}$ approach (the $\mathrm{OH}$-ness) was assessed using the framework developed by the NEOH. This study summarizes the results of assessing the operations and supporting infrastructure of the initiative by estimating the OH-index (Fig. 1).

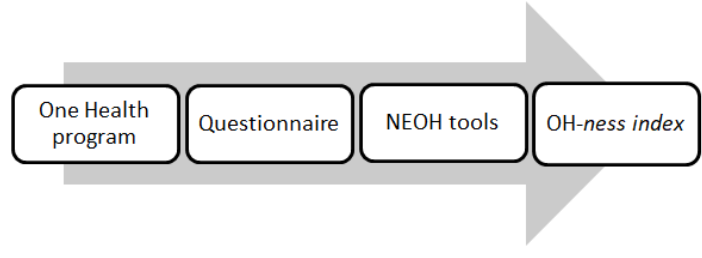

Fig. 1. The One Health evaluation steps.

\section{RESULTS}

\section{A. Operations aspect}

One Health thinking is one of three attributes of the operations aspect of the $\mathrm{OH}$ initiative. It is used to evaluate the way actors and stakeholders think about the $\mathrm{OH}$ initiative and the system in which it operates. The $\mathrm{OH}$ thinking of the initiative has a score of 0.8 on dimensions coverage and balance, 1.0 on initiative to environment match, 1.0 on integrated health approach, 0.7 on system features and targets, 0.9 on sustainability and socio- ecological considerations, and 0.8 on perspectives and theory of change (TOC) factors (Fig. 2).

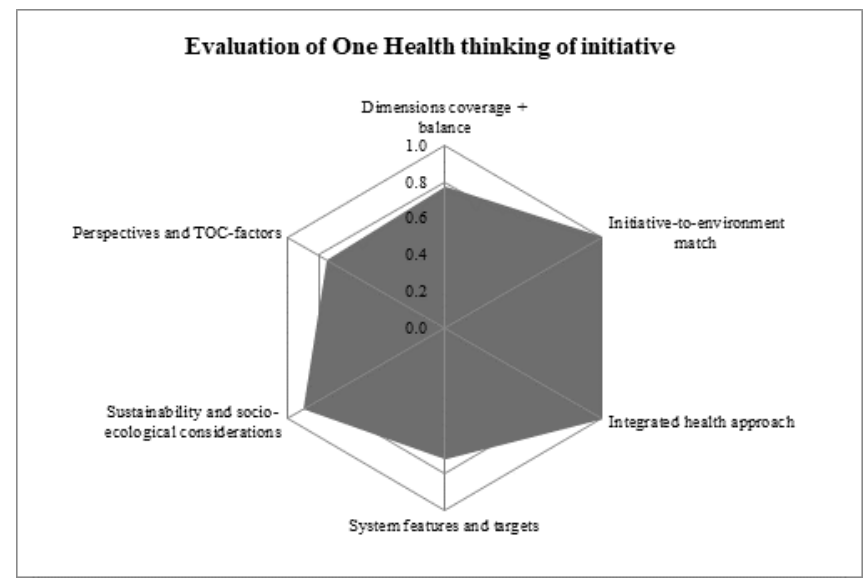

Fig. 2. The spider diagram of $\mathrm{OH}$ thinking of $\mathrm{OH}$ initiative in Indonesia.

The second attribute of the operations aspect is $\mathrm{OH}$ planning, which is utilized to evaluate the established aims, problem formulation, roles, tasks, responsibilities and competencies. Overall, two components of $\mathrm{OH}$ planning of the initiative which are common aims and strengthening capacities for One Health-focused, effective and sustainable prevention and control of targeted zoonoses and EIDs have a score of 1.0, while the stakeholder and actor engagement as well as the self-assessment and plan revisions components have a score of 0.9 (Fig. 3).

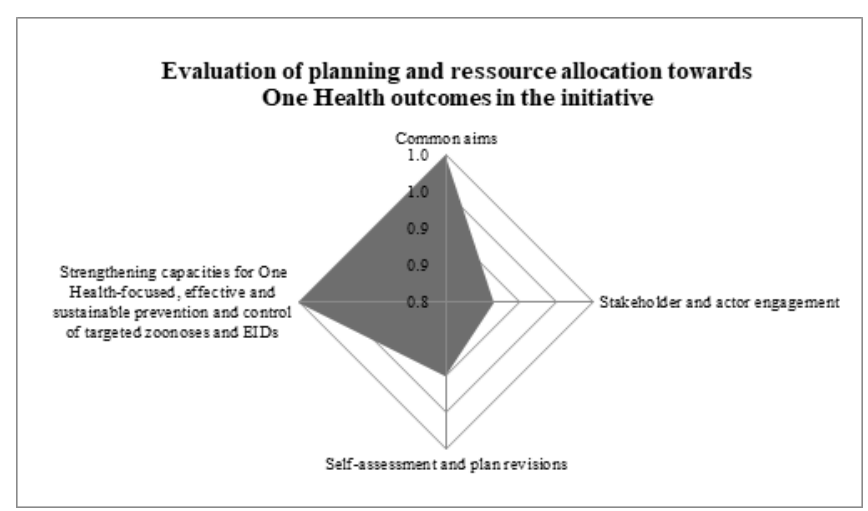

Fig. 3. The spider diagram of $\mathrm{OH}$ planning of $\mathrm{OH}$ initiative in Indonesia.

The last attribute of the operations aspect is the degree to which the initiative works towards the achievement of $\mathrm{OH}$ outcomes. This attribute is used to evaluate the interdisciplinary and participatory engagement in the initiative. The attribute has a score of 0.7 on the flexibility and adaptation aspect, 0.8 on collaboration, 0.9 on broadness of initiative and transdisciplinary balance, and 1.0 on cultural and social balance (Fig. 4). 


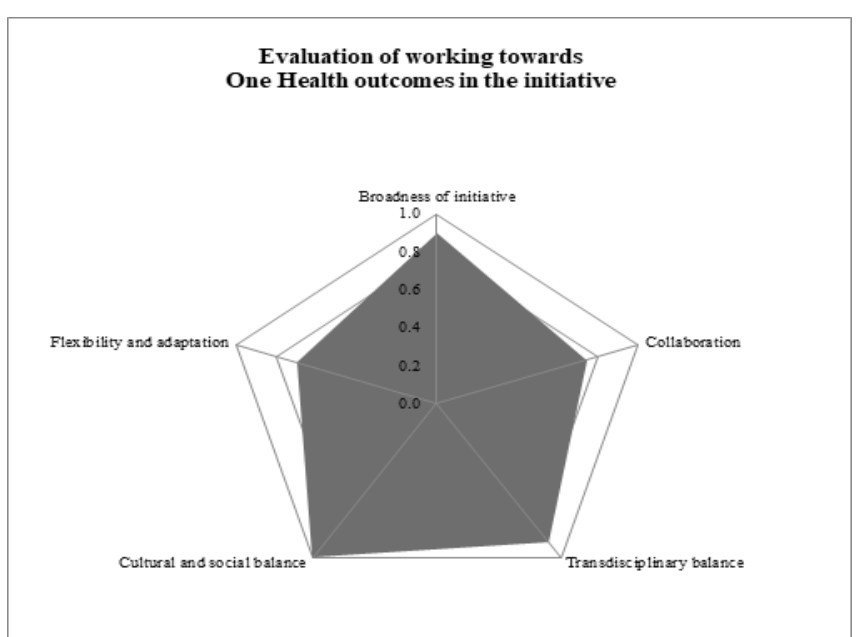

Fig. 4. The spider diagram of $\mathrm{OH}$ working of $\mathrm{OH}$ initiative in Indonesia.

\section{B. Supporting infrastructure aspect}

Similar to the operations aspect, the supporting infrastructure aspect has three attributes: Sharing, Learning and Organisation. "Sharing" is used to evaluate the extent and methods for information and data sharing infrastructure associated with the initiative. This attribute has a score of 0.6 on general information or awareness sharing, 0.8 on data and information sharing as well as institutional memory or resilience, and 0.9 for the methods and results sharing component (Fig. 5).

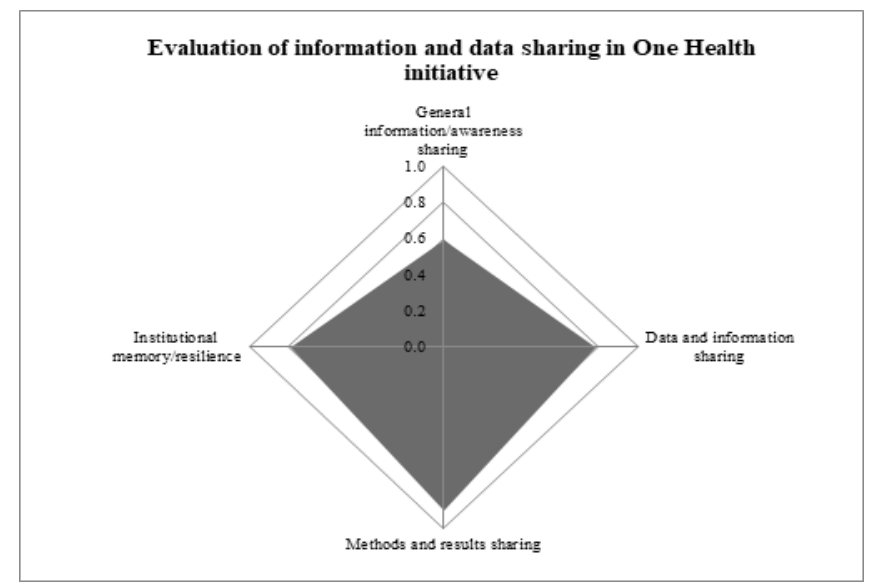

Fig. 5. The spider diagram of sharing attribute of $\mathrm{OH}$ initiative in Indonesia.

The second attribute of the supporting infrastructure aspect is learning for individual, team and organization level, which consists of basic, adaptive and generative learning. While for environmental level, it only consists of adaptive and generative learning. The evaluation results showed individual and organizational levels have a score of 0.5 , team level has a score of 0.7 , and 0.8 score for direct and general environment supportive (Fig. 6).

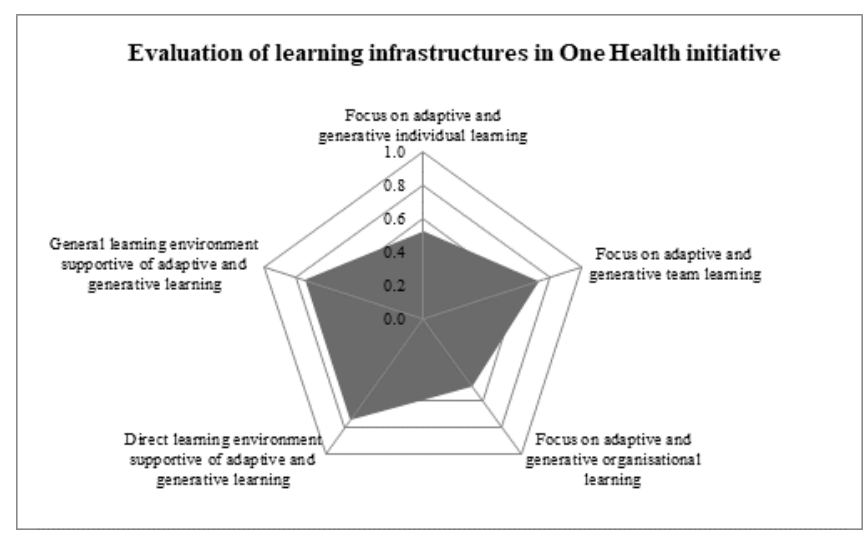

Fig. 6. The spider diagram of $\mathrm{OH}$ initiative's learning in Indonesia.

The final attribute is systemic organization which refers to how well the management structure matches and supports the initiative's goal and combinantion of disciplines and fields of expertise. The attribute has a score of 0.67 on social and leadership structures and skills, and 0.8 on team structures, competence as well as on focus and innovation (Fig. 7).

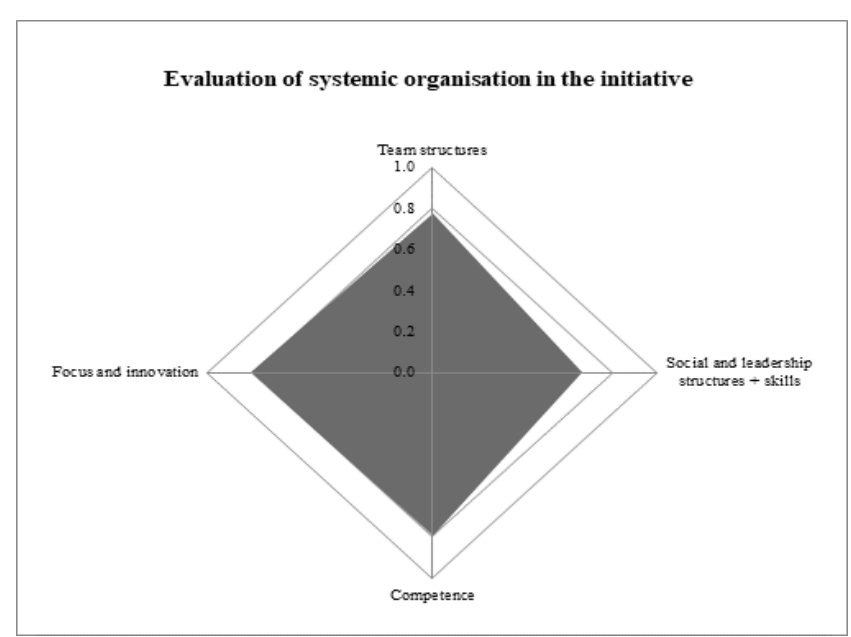

Fig. 7. The spider diagram of sistemic organisation attribute of $\mathrm{OH}$ initiative in Indonesia.

Based on the data collected in all pilots and the evaluation using $\mathrm{NEOH}$ tools, the initiative has an overall $\mathrm{OH}$-ness score of 0.74 (out of 1). The spider graph above indicated that the initiative incorporates effectively the $\mathrm{OH}$ approach, both in the operations and the supporting infrastructure dimensions. 


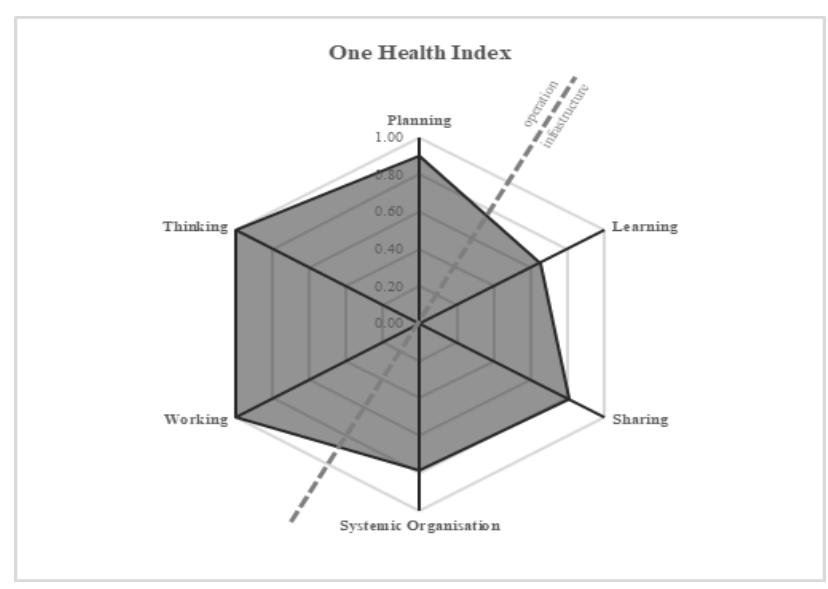

Fig. 8. The spider diagram of $\mathrm{OH}-$ ness of the $\mathrm{OH}$ initiative.

\section{DISCUSSION}

It is believed that the $\mathrm{OH}$ approach is complex and difficult to implement at the field level. There is limited technical guidance available on disease prevention and control regarding the practical design and the implementation of $\mathrm{OH}$ programs [9]. The Indonesian Government has been piloting $\mathrm{OH}$ programs in order to prevent and control targeted zoonotic diseases and EIDs for four years. A series of $\mathrm{OH}$ activities have been carried out since January 2016 for field officers from each of the three sectors (public health, animal health, and environment and forestry) in four $\mathrm{OH}$ pilot districts, Minahasa, Boyolali, Ketapang, and Bengkalis. By using the NEOH tools to evaluate this initiative, evidence supporting the application of this approach was generated and it showed that the $\mathrm{OH}$ approach can be conceptualized, planned and carried out at the field level.

This is an important step towards identifying added value arising from integration across disciplines and sectors [7]. The zoonoses prevention and control programme in Indonesia incorporates effectively the $\mathrm{OH}$ approach, both in its operations and the associated infrastructure. According to the data collected in four pilot areas, the initiative has a $\mathrm{OH}$-ness index score of 0.74 , with a score of 1.0 on $\mathrm{OH}$ thinking and $\mathrm{OH}$ working, 0.9 on $\mathrm{OH}$ planning, 0.81 on $\mathrm{OH}$ sharing, 0.65 on $\mathrm{OH}$ learning and 0.79 on systemic organization. These scores indicate that this programme is a good example of how $\mathrm{OH}$ can be implemented in Indonesia. However, there is still room for improvement of the $\mathrm{OH}-$ ness attributes of the initiative.

One of the limitations of this study relates to the data that has been used. The data obtained from the field only covered $24 \%(78 / 320)$ of the field staff involved in the programme. However, all sectors and pilot districts had representative data for the evaluation. Of 78 respondents involved in the study, $41 \%(32 / 76)$ was from the animal health sector, $34 \%$ (27/76) from the public health sector, and $25 \%$ (19/78) from the environment and forestry sector. In terms of staff distribution, 25 respondents (32\%) were from Minahasa, $18(23 \%)$ from Boyolali, 22 (29\%) from Ketapang, and 13 (16\%) from Bengkalis.
For further research, it is recommended to conduct an economic evaluation of the initiative to prove the effectiveness of the implementation cost. Economic evaluation is an effective tool in convincing decision makers and communities of the benefits in moving towards improved risk assessment and management. It can provide solid evidence of the cost-effectiveness of different programmes, looking at the costs and benefits from a multidimensional perspective. This approach can assist in improving public health systems and contribute to shifting from a resource-intensive and sectoral response to disease events to a more effective prevention and early warning system under the $\mathrm{OH}$ umbrella. Moreover, the results of the evaluation can be used to make a decision on scaling up (or not) this programme in Indonesia.

\section{ACKNOWLEDGMENT}

The author's appreciation and gratitude goes to the Indonesian Coordinating Ministry for Human Development and Cultural Affairs, the Indonesian Ministry of Agriculture, the Indonesian Ministry of Health, the Indonesian Ministry of Environment and Forestry, the Indonesian Veterinary Faculties Association, the Food and Agriculture Organization of the United Nations (UN-FAO), and the United States Agency for International Development (USAID).

\section{REFERENCES}

[1] J.S. Mackenzie, M. McKinnon, and M. Jeggo, "One Health: From Concept to Practice", in Confronting Emerging Zoonoses, A. Yamada et al., Japan: Springer, 2014, pp. 163-189.

[2] E.P.J. Gibbs, "The evolution of One Health: a decade of progress and challenges for the future", in Veterinary Record 10.1136/vr.g143, pp. 85-91, January 2014.

[3] W.A. Gebreyes et al., "The Global One Health Paradigm: Challenges and Opportunities for Tackling Infectious Diseases at the Human, Animal, and Environment Interface in Low-Resource Settings", PLOS Negl. Trop. Dis., vol. 8, in press.

[4] W. Katip, P. Kanjanarat, R. Mektrirat, N. Kasatpibal, "Using One Health Approach to Address Challenges of Antimicrobial Resistance and Inappropriate Use of Antibiotics Through Training of Future Health Workforces", The Southeast Asia J. Trop. Med. Pub. Health, vol. 49(1), pp. 36-42, in press.

[5] J. Angelos, A. Arens, H. Johnson, J. Cadriel, B. Osburn, "One Health in foos safety and security education: A curricular framework", Elsevier, J. Compar. Immun. Microb. Infect. Dis., vol. 44, pp. 29-33, February 2016.

[6] K. Lee, Z.L. Brumme, "Operationalizing the One Health approach: the global governance challenges", Health Policy and Planning, vol 28 , pp. $778-785$.

[7] S.R. Ruegg et al., "A Systems Approach to Evaluate One Health Initiatives”, Frontiers, Vet. Sci., vol. 5, March 2018.

[8] FAO Emergency Centre for Transboundary Animal Diseases (ECTAD), Annual Report 2016: Protecting lives and livelihoods, [FAO] The Food and Agriculture Organization of the United Nations, Jakarta, 2017.

[9] J. Lebov, K. Grieger, D. Womack, D. Zaccaro, N. Whitehead, B. Kowalcyk, P.D.M. MacDonald, "A framework for One Health Research”, One Health, vol. 3, pp. 44-50, March 2017. 